\title{
Current Perspectives on Antithrombotic Therapy for the Treatment of Acute Coronary Syndrome
}

\author{
Korakoth Towashiraporn (1D', Rungroj Krittayaphong ${ }^{2}$ \\ 'Her Majesty Cardiac Center, Faculty of Medicine Siriraj Hospital, Mahidol University, Bangkok, Thailand; ${ }^{2}$ Department of Medicine, Faculty of \\ Medicine Siriraj Hospital, Mahidol University, Bangkok, Thailand \\ Correspondence: Rungroj Krittayaphong, Division of Cardiology, Department of Medicine, Faculty of Medicine Siriraj Hospital, Mahidol University, 2 \\ Wanglang Road, Bangkoknoi, Bangkok, 10700, Thailand, Tel +66 2-419-6104, Fax +66 2-412-7412, Email rungroj.kri@mahidol.ac.th
}

\begin{abstract}
Acute coronary syndrome (ACS) is one of the leading causes of death worldwide. Percutaneous coronary intervention (PCI) is the treatment of choice for ACS as this procedure reduces the morbidity and mortality rates of patients in clinical trials and daily practice. However, patients with a history of prior ACS who undergo PCI are still at high risk for recurrent major adverse cardiac events (MACE). Because the antithrombotic drugs reduce the rate of MACE and minimize stent-related complications such as target vessel failure or stent thrombosis, the utilization of these agents is the cornerstone treatment for secondary prevention of ACS patients after PCI. Unfortunately, using the antithrombotic agents may be associated with bleeding complications, including major or fatal bleeding. Therefore, premature discontinuation of antithrombotic regimens regarding the hemorrhagic events is sometimes inevitable and possibly leads to fatal complications such as stent thrombosis. To minimize the bleeding issues, shorten antithrombotic regimens have been proposed, which theoretically offers improved safety. Nevertheless, inappropriate withdrawal of antithrombotic drugs may increase the rate of ischemic events. On the other hand, an unnecessary prolonged antithrombotic regimen may cause avoidable bleeding. Balancing the risk of bleeding against the benefits of using antithrombotic drugs is therefore challenging especially for the patients who contain both bleeding and ischemic risks such as ACS patients who are concomitant using the anticoagulants. Currently, the treatment paradigms are shifting from the "one size fits all approach" toward the "tailored approach". This means that the antithrombotic regimens can be adjustable individually. As a result, various clinical risk scoring systems have been established to help physicians with their decision-making. However, besides the development of these dedicated scoring tools, clinical judgment for balancing the safety versus the efficacy before deciding on the antithrombotic plan is still imperative.

Keywords: balancing ischemic and bleeding risks, dual antiplatelet therapy, dual antithrombotic therapy, individualized antithrombotic regimens, triple antithrombotic therapy
\end{abstract}

\section{Introduction}

Acute coronary syndrome (ACS), which consists of non-ST segment elevation ACS (NSTE-ACS) [whether unstable angina (UA) or non-ST-segment elevation myocardial infarction (NSTEMI)] and ST-segment elevation myocardial infarction (STEMI), is one of the most significant causes of mortality worldwide. ${ }^{1-3}$ Patients with a history of previous ACS are at high risk of rehospitalization and recurrent major adverse cardiac events (MACE), ${ }^{4,5}$ which cause substantial socioeconomic burdens. ${ }^{6}$ Secondary prevention with antithrombotic agents is the cornerstone treatment for ACS as this strategy minimizes the rate of future repeated ischemic events. ${ }^{7}$ However, patients can suffer bleeding complications caused by the antithrombotic drugs. Consequently, premature discontinuation of antithrombotic therapy due to hemorrhage can cause fatal side effects, especially stent thrombosis. ${ }^{8}$ In contrast, inadequate antithrombotic treatment can contribute to unfavorable ischemic outcomes. As a result, balancing the risk of bleeding against the risk of ischemia is always a challenge in daily practice. This article discusses current perspectives on antithrombotic therapy for the treatment of ACS.

\section{Antiplatelet Therapy for Patients Undergoing Percutaneous Coronary Intervention}

Dual antiplatelet therapy (DAPT), which is the combination of aspirin and $\mathrm{P}^{2} \mathrm{Y}_{12}$ inhibitors (clopidogrel, prasugrel, and ticagrelor), is the mainstay pharmacological therapy for the secondary prevention of ACS and percutaneous coronary 
intervention (PCI). Current clinical practice guidelines recommend the newer and more potent $\mathrm{P}_{2} \mathrm{Y}_{12}$ inhibitors (prasugrel and ticagrelor) over clopidogrel. ${ }^{9} 10$ Nevertheless, these newer inhibitors carry a higher risk of severe bleeding than clopidogrel. ${ }^{11-13}$ The risk of bleeding complications versus the benefit of reducing ischemic events should therefore be considered.

The CURE (Clopidogrel in Unstable Angina to Prevent Recurrent Ischemic Events) trial ${ }^{14}$ was the first clinical trial to demonstrate the efficacy of DAPT using clopidogrel (300-mg loading dose, followed by $75 \mathrm{mg}$ daily) and aspirin (162-to -325-mg loading dose, then 75 to $325 \mathrm{mg}$ daily) in patients with NSTE-ACS. Compared to placebo, DAPT significantly decreased the incidence of combined ischemic endpoints relative to single antiplatelet therapy with aspirin. However, the risk of major bleeding increased when clopidogrel was used.

There are several concerns about the pharmacokinetic limitations of clopidogrel. ${ }^{15}$ This prodrug requires two-step oxidation by the cytochrome P450 system to generate its active compound. Consequently, several hours are needed after administering clopidogrel before its maximum platelet inhibition effects are achieved. ${ }^{16}$ Furthermore, genetic variations that affect clopidogrel metabolism result in a more unpredictable and lower platelet inhibition than the more potent $\mathrm{P} 2 \mathrm{Y}_{12}$ inhibitors. Clopidogrel high-on treatment platelet reactivity leads to severe adverse cardiac events, especially stent thrombosis ${ }^{17-19}$ and cardiovascular death. ${ }^{20}$

Still, there is currently no evidence to support the routine use of genotype-guided $\mathrm{P} 2 \mathrm{Y}_{12}$ inhibitor therapy. The TAILOR-PCI (Tailored Antiplatelet Initiation to Lessen Outcomes Due to Decreased Clopidogrel Response after Percutaneous Coronary Intervention) trial investigated the effectiveness of point-of-care genetic testing for cytochrome P450 2C19 to guide a P2Y 12 inhibitor strategy for PCI. Even though it was the largest clinical trial to have focused on genotype-guided $\mathrm{P} 2 \mathrm{Y}_{12}$ inhibitor therapy, it was unable to meet its primary composite efficacy endpoints at the 12-month follow-up. ${ }^{21}$ The 2014 American Heart Association (AHA)/ American College of Cardiology (ACC) Guideline for the Management of Patients With Non-ST-Elevation Acute Coronary Syndromes does not recommend routine genetic phenotype testing. ${ }^{22}$

CURRENT-OASIS 7 (Clopidogrel and Aspirin Optimal Dose Usage to Reduce Recurrent Events-Seventh Organization to Assess Strategies in Ischemic Syndromes) was a two-by-two factorial design study of patients with ACS. It compared a 7-day double-dose clopidogrel regimen (600-mg loading dose; $150 \mathrm{mg}$ daily for 6 days; $75 \mathrm{mg}$ daily thereafter) with the standard clopidogrel regimen (300-mg loading dose; $75 \mathrm{mg}$ daily thereafter), using high-dose aspirin (300-325 mg daily) and low-dose aspirin (75-100 mg daily). There were no significant differences in the primary efficacy endpoints of the double- and standard-dose clopidogrel regimens, or of lower- and higher-dose aspirin. ${ }^{23}$ In a prespecified subgroup analysis of 17,263 participants (69\%) who underwent PCI, the 7-day double-dose clopidogrel regimen reduced the incidence of adverse cardiovascular events and stent thrombosis. However, the regimen also demonstrated a significantly higher incidence of major bleeding. ${ }^{24}$ The double-dose approach aims to overcome the adverse effects of high on-treatment platelet reactivity to treatment with clopidogrel. Its use should be strictly restricted to patients at a very high risk of thrombotic events and without a significant bleeding risk who proceed to PCI, when a more potent $\mathrm{P} 2 \mathrm{Y}_{12}$ inhibitor is not available.

The 2020 European Society of Cardiology (ESC) guidelines for the management of ACS in patients presenting without persistent ST-segment elevation recommend the use of clopidogrel only when prasugrel and ticagrelor are unavailable, cannot be tolerated, or are contraindicated. The recommended loading dose of clopidogrel is 300-600 mg and the daily maintenance dose is $75 \mathrm{mg}$. The class of recommendation is I, and the level of evidence is C. ${ }^{9}$

\section{Potent $\mathbf{P 2 Y}_{12}$ Inhibitors}

The potent $\mathrm{P} 2 \mathrm{Y}_{12}$ inhibitors (prasugrel and ticagrelor) provide faster onset, greater consistency, and greater platelet inhibition than clopidogrel. ${ }^{15,25-28}$ These 2 drugs have been thoroughly investigated in head-to-head comparisons with clopidogrel in pivotal Phase 3, randomized controlled trials.

The Trial to Assess Improvement in Therapeutic Outcomes by Optimizing Platelet Inhibition with PrasugrelThrombolysis in Myocardial Infarction (TRITON-TIMI) 38 compared the efficacies of prasugrel (60-mg loading dose and 10-mg daily maintenance dose) and clopidogrel (300-mg loading dose, followed by a dose of 75-mg daily). It found that in patients with ACS for whom PCI was planned, prasugrel was superior in terms of reducing the incidence of 
ischemic events, ${ }^{12}$ including definite or probable stent thrombosis, ${ }^{29}$ recurrent myocardial infarction, ${ }^{30}$ and recurrent cardiovascular events. ${ }^{31}$ It should be noted that $99 \%$ of the participants underwent PCI. However, the rates of major bleeding and fatal bleeding were significantly higher when prasugrel was used. In addition, a post hoc analysis revealed 2 populations for whom the net clinical benefits of prasugrel were lower: patients aged $\geq 75$ years, and patients with a body weight $(\mathrm{BW})<60 \mathrm{~kg}$. The analysis also identified a subgroup that was potentially at risk for bleeding complications: patients with a history of stroke or transient ischemic attack (TIA). ${ }^{12}$ As a result, the US Food and Drug Administration and the European Medicines Agency (EMA) have stated that the contraindications of prasugrel are patients with a history of stroke or TIA. In the case of patients aged $\geq 75$ years and those with a $\mathrm{BW}<60 \mathrm{~kg}$, the organizations have also advised that the use of prasugrel should be limited or the dose should be reduced to $5 \mathrm{mg}$ per day. ${ }^{32}$ In a subgroup analysis of patients eligible for prasugrel (age $<75$ years, BW $>60 \mathrm{~kg}$, and no history of stroke or TIA), prasugrel was found to have a net clinical benefit. ${ }^{32}$ Additional evidence in support of prasugrel came from a subgroup analysis of 10,074 NSTE-ACS patients in the TRITON-TIMI 38 trial who met the EMA criteria for the use of prasugrel. The analysis demonstrated the efficacy of the agent in reducing the incidence of primary ischemic endpoints without increasing bleeding outcomes. ${ }^{33}$ All of this evidence informs treating physicians to strictly use prasugrel in populations that meet the approved criteria to achieve the greatest therapeutic benefits without increasing the likelihood of bleeding complications.

The 2020 NSTE-ACS guidelines recommend the use of prasugrel in addition to aspirin for $\mathrm{P}_{2} \mathrm{Y}_{12}$ receptor inhibitornaive patients who are scheduled for PCI. The recommended loading dose of prasugrel is $60 \mathrm{mg}$ and the maintenance dose is $10 \mathrm{mg}$ daily. The guidelines recommend reducing the maintenance dose to $5 \mathrm{mg}$ per day for patients aged $\geq 75$ years and for those with a BW $<60 \mathrm{~kg}$, but using the same loading dose of $60 \mathrm{mg}$ as the standard protocol. The class of recommendation is I, and the level of evidence is B. ${ }^{9}$

The PLATO (Platelet Inhibition and Patient Outcomes) trial demonstrated that the use of ticagrelor (180-mg loading dose, followed by a dose of $90 \mathrm{mg}$ twice daily) with aspirin (325-mg loading dose for those who had not previously been receiving aspirin, followed by $75-100 \mathrm{mg}$ daily. The 325-mg daily dose could be used for 6 months after stent implantation) as the DAPT regimen decreased vascular death, myocardial infarction, and stroke in patients with ACS with or without ST-segment elevation, relative to clopidogrel (300-to-600-mg loading dose, $75 \mathrm{mg}$ daily thereafter). The primary efficacy endpoints were driven by the lower rate of death from vascular causes and myocardial infarction. ${ }^{11}$ A subgroup analysis of the patients who underwent PCI ( $61 \%$ of all participants) revealed that ticagrelor also decreased the rate of stent thrombosis. ${ }^{34}$ It is noteworthy that an aspirin dosage of more than $100 \mathrm{mg}$ per day was found to negate the clinical benefits of ticagrelor. ${ }^{35}$ Therefore, a low aspirin dosage $(\leq 100 \mathrm{mg} /$ day) should be administered when aspirin is used concurrently with ticagrelor. For adverse events, the rate of non-coronary artery bypass graft (CABG)-related major bleeding and the incidence of dyspnea were significantly higher for patients receiving ticagrelor. ${ }^{11}$

Using ticagrelor in older patients should be done with caution, given the high risk for bleeding complications. The Patient Outcome after Primary PCI (POPular) AGE trial demonstrated that ticagrelor administration in patients with NSTE-ACS who were older than 70 years significantly increased the incidence of bleeding events. Compared to clopidogrel, there was a similar incidence of the combined endpoint of all-cause death, myocardial infarction, stroke, and bleeding. ${ }^{36}$ Of note, the treatment drug was prematurely discontinued for $47 \%$ of the patients in the ticagrelor group and for $22 \%$ in the clopidogrel group. As a result, the investigators suggested considering clopidogrel as an alternative antiplatelet agent to ticagrelor for older patients.

\section{Pretreatment with Potent Antiplatelet Therapy for NSTE-ACS Patients Undergoing PCI}

The ACCOST (A Comparison of Prasugrel at PCI or Time of Diagnosis of Non-ST Elevation Myocardial Infarction) trial aimed to assess the benefits of prasugrel pre-treatment by randomly assigning 4033 patients with non-ST elevation myocardial infarction (NSTEMI) into prasugrel pretreatment and control groups. The pretreatment group received $30 \mathrm{mg}$ of prasugrel at the time of NSTEMI diagnosis and an additional $30 \mathrm{mg}$ of prasugrel immediately before PCI (giving a total loading dose of $60 \mathrm{mg}$ ). The corresponding patients in the control group received placebo at the time of NSTEMI 
diagnosis and the standard loading dose of $60 \mathrm{mg}$ of prasugrel immediately before PCI. The results showed that the pretreatment strategy did not produce significant benefits in terms of a reduction in ischemic events for up to 30 days after the randomization. Furthermore, the rate of Thrombolysis In Myocardial Infarction (TIMI) major bleeding was significantly higher for the pretreatment group. In a prespecified subgroup analysis of 2770 patients with NSTEMI who underwent PCI, the pretreatment strategy was still unable to reduce ischemic events, with an increased rate of bleeding at 7 and 30 days from randomization. ${ }^{37}$ The ischemic events were $8.5 \%$ and $8.4 \%$ for the pretreatment and control groups at day 7 (hazard ratio [HR], $1.01 ; 95 \% \mathrm{CI}, 0.78-1.31 ; \mathrm{P}=0.92$ ) and $9.2 \%$ and $8.8 \%$ at day 30 (HR, $1.05 ; 95 \% \mathrm{CI}, 0.82-$ $1.34 ; \mathrm{P}=0.72$ ). The non-CABG related major or minor bleeding events were $3.4 \%$ and $1.2 \%$ for the pretreatment and control groups at day $7(\mathrm{HR}, 2.94 ; 95 \% \mathrm{CI}, 1.67-5.18$; P $<0.001)$ and $4.2 \%$ and $1.4 \%$ at day 30 (HR, 3.11; 95\% CI, 1.86-5.22; $\mathrm{P}<0.001$ ). The evidence from the ACCOST trial supports the use of prasugrel only when the coronary anatomy is already documented. ${ }^{38}$

The SCAAR (Swedish Coronary Angiography and Angioplasty Registry) reported that pretreatment with $\mathrm{P} \mathrm{Y}_{12}$ inhibitors in 64,857 patients with NSTEMI was associated with an increased risk of bleeding without any ischemic benefits. ${ }^{39}$ Of the patient cohort, $43.7 \%$ had been pretreated with clopidogrel, $54.5 \%$ with ticagrelor, and $1.8 \%$ with prasugrel

The 2020 NSTE-ACS guidelines do not recommend the use of a routine pretreatment strategy with a $\mathrm{P}_{2} \mathrm{Y}_{12}$ receptor inhibitor in patients whose coronary anatomy is unknown and who are scheduled for early invasive management. The class of recommendation is III, and the level of evidence is A. ${ }^{9}$

\section{Comparison of Potent Antiplatelet Therapies}

Several studies have compared the 2 potent $\mathrm{P}_{2} \mathrm{Y}_{12}$ inhibitors, prasugrel and ticagrelor. The PRAGUE (Comparison of Prasugrel and Ticagrelor in the Treatment of Acute Myocardial Infarction) 18 trial compared their safety and efficacy in STEMI patients who underwent primary PCI. This study, which terminated prematurely, did not show significant differences in the occurrence of combined primary and secondary endpoints of prasugrel and ticagrelor. ${ }^{40}$

An analysis was conducted of real-world data held by the British Cardiovascular Intervention Society (BCIS) PCI registry. The cohort study analyzed 89,067 primary PCI procedures performed on patients with STEMI in England and Wales between 2007 and 2014. It was found that prasugrel demonstrated superior 30-day and 1-year mortality benefits to clopidogrel and ticagrelor. ${ }^{41}$

The ISAR-REACT (Intracoronary Stenting and Antithrombotic Regimen: Rapid Early Action for Coronary Treatment) 5 trial investigated 4018 patients with ACS who were scheduled to receive the invasive strategy. Approximately $40 \%$ of the patients presented with STEMI. The study demonstrated that a ticagrelor pretreatment strategy was inferior to deferred loading of prasugrel when coronary anatomy was known. The rates of adverse events (death, myocardial infarction, and stroke at 1 year) were significantly higher for the ticagrelor group. However, the 2 groups had similar rates of bleeding. ${ }^{42}$

The 2020 NSTE-ACS guidelines suggest the use of prasugrel in preference to ticagrelor for patients with NSTE-ACS who are scheduled to proceed to PCI. The class of recommendation is IIa, and the level of evidence is B. ${ }^{9}$

\section{Duration of Antiplatelet Regimen}

The antiplatelet regimen strategy should be designed to achieve adequate ischemic protection. ESC guidelines offer a default DAPT regimen strategy that can be used after PCI for patients with ACS (both STEMI and NSTE-ACS). More specifically, the guidelines recommend the use of a potent $\mathrm{P} 2 \mathrm{Y}_{12}$ inhibitor (prasugrel or ticagrelor) over clopidogrel. The agent should be accompanied by low-dose aspirin (75-100 mg per day) for up to 12 months, unless there are contraindications. ${ }^{9,10}$

For patients with NSTE-ACS with special considerations, the 2020 ESC guidelines for the treatment of ACS in patients who present without persistent ST-segment elevation encourage tailoring of the DAPT regimen for individual patients. In particular, the regimen should be based on the relative ischemic and bleeding risks of each patient. ${ }^{9}$

Several trials have investigated the benefits of shortening the DAPT regimen with respect to the indications for ACS. The TICO (Ticagrelor Monotherapy After 3 Months in the Patients Treated with New Generation Sirolimus-Eluting Stent 
for Acute Coronary Syndrome) trial investigated 3056 patients with ACS who were treated with PCI with the bioresorbable polymer sirolimus-eluting stent Orsiro (Biotronik AG). The trial compared the standard 12-month ticagrelor-based DAPT with 3 months of DAPT followed by ticagrelor monotherapy. At the 1-year follow-up, the study found that patients on the modified regimen had a significantly reduced incidence of net adverse clinical events (a composite outcome of major bleeding and cardiovascular events). ${ }^{43}$ The TWILIGHT (Ticagrelor with Aspirin or Alone in High-Risk Patients After Coronary Intervention) trial, a double-blind design, studied patients at high risk of bleeding or ischemic events who underwent PCI. Compared to the standard 12-month DAPT, 3 months of DAPT followed by ticagrelor monotherapy reduced the incidence of clinically relevant bleeding without increasing ischemic events. ${ }^{44}$ It is worth noting that the rate of ischemic events in TWILIGHT was low compared to other trials, and its participants did not have a high risk of bleeding under current bleeding risk criteria. ${ }^{9}$

The GLOBAL LEADERS trial compared the shortened DAPT regimen (1 month of aspirin plus ticagrelor) followed by 23 months of ticagrelor monotherapy $(\mathrm{n}=7980)$ with the standard 12 months DAPT regimen (aspirin plus either clopidogrel or ticagrelor) followed by 1 year of aspirin monotherapy $(\mathrm{n}=7988)$ among patients undergoing PCI with a biolimus-eluting BioMatrix Flex stent (Biosensors). At a 2-year follow-up period, the shortened DAPT regimen failed to demonstrated superiority to the standard DAPT regimen in the prevention of all-cause mortality or new Q-wave myocardial infarction [95\% CI $0.75-1.01 ; \mathrm{P}=0.073]^{43}$

The Short and Optimal Duration of Dual Antiplatelet Therapy After Everolimus-Eluting Cobalt-Chromium Stent-2 (STOPDAPT-2) trial randomized 3045 patients who underwent PCI with the cobalt-chromium everolimus-eluting Xience stent (Abbott Vascular) to receive 1-month DAPT followed by clopidogrel monotherapy or the standard 12 months DAPT. At a 1-year follow-up period, the 1-month DAPT regimen significantly lower composite endpoints of ischemic and bleeding events (2.4\% [1-month DAPT] versus 3.7\% [12-month DAPT]; HR, 0.64;95\% CI, 0.42-0.98; P < 0.001 for noninferiority; $\mathrm{P}=0.04$ for superiority). ${ }^{45}$ Nevertheless, among patients in the STOPDAPT- 2 trial who underwent ACSPCI (38\% of overall populations: STEMI 56\%, NSTEMI $20 \%$, and UA $24 \%$ ) which was reported in the STOPDAPT-2 ACS trial, the 1-month DAPT regimen failed to meet the criteria for noninferiority compared with the standard 12-month DAPT for the occurrence of combined efficacy and safety endpoints (3.2\% [1-month DAPT] versus 2.8\% [12-month DAPT]; HR 1.14, 95\% CI 0.80-1.62; $\mathrm{P}=0.06$ for noninferiority). ${ }^{46}$ Moreover, the 1-month DAPT was associated with almost two times of increased risk of myocardial infarction (1.6\% [1-month DAPT] versus 0.9\% [12-month DAPT]; HR $1.91,95 \%$ CI 1.06-3.44; P < 0.05). The evidence from the STOPDAPT-2 ACS trial was compatible with the data derived from the 6-month versus 12-month or longer dual antiplatelet therapy after percutaneous coronary intervention in patients with acute coronary syndrome (SMART-DATE) trial which demonstrated the increased risk of myocardial infarction with 6-month DAPT compared to the 12-months regimen for ACS-PCI using DES (1.8\% [6-month DAP] versus 0.8\% [12month DAPT]; P = 0.02). ${ }^{47}$

A Randomized Controlled Trial With Resolute Onyx in One Month Dual Antiplatelet Therapy (DAPT) for HighBleeding Risk Patients (Onyx ONE) trial compared the polymer-free drug-coated BioFreedom stent (BioSensors Interventional Technologies) with the polymer-based zotarolimus-eluting Resolute Onyx stent (Medtronic) in high bleeding risk patients who underwent PCI. This study enrolled 1996 patients (62\% had ACS) at high bleeding risk to receive zotarolimus-eluting stents or polymer-free drug-coated stents. The enrolled populations were treated with 1-month DAPT, then single antiplatelet therapy with aspirin after PCI. At 1-year follow-up, the zotarolimus-eluting stents were non-inferior to the polymer-free drug-coated stent group in terms of the occurrence of the composite of death from cardiac causes, myocardial infarction, or stent thrombosis (17.1\% [zotarolimus-eluting stent] versus 16.9\% [polymer-free drug-coated stent]; $\mathrm{P}=0.01$ for noninferiority). ${ }^{48}$ At the 2-year follow-up, the incidences of the primary composite endpoints were still similar between groups (21.2\% [zotarolimus-eluting stent] versus $20.7 \%$ [polymer-free drug-coated stent]; $95 \% \mathrm{CI}-3.1-4.2 ; \mathrm{P}=0.78) .{ }^{49}$

The Management of High Bleeding Risk Patients Post Bioresorbable Polymer Coated Stent Implantation With an Abbreviated Versus Prolonged DAPT Regimen (MASTER DAPT) trial investigated the high-bleeding risk patients who underwent PCI with the biodegradable-polymer sirolimus-eluting coronary stent Ultimaster (Terumo). The trial compared the 1-month DAPT regimen (abbreviated therapy) with the standard DAPT regimen (2-months DAPT with an indication for oral anticoagulation or 5-months DAPT without an indication for oral anticoagulation). At 1-year follow-up, the study 
found that the abbreviated antiplatelet therapy was non-inferior to the standard antiplatelet therapy regarding the net adverse clinical events (all-cause mortality, MI, stroke, or major bleeding): 7.5\% [the abbreviated therapy group] versus $7.7 \%$ [the standard therapy group]; $\mathrm{P}<0.001$ for noninferiority and the major adverse cardiac or cerebral events (allcause mortality, MI, or stroke): $6.1 \%$ [the abbreviated therapy group] versus $5.9 \%$ [the standard therapy group]; $\mathrm{P}=$ 0.001 for noninferiority. The abbreviated therapy group significantly reduced the incidence of major or clinically relevant nonmajor bleeding: (6.5\% [the abbreviated therapy group] versus $9.4 \%$ [the standard therapy group]; $\mathrm{P}<0.001$ for superiority). ${ }^{50}$

The XIENCE 28 and the XIENCE 90 trials investigated the safety of one-month (28) or three-month (90) DAPT in high bleeding risks patients who undergoing PCI with the XIENCE everolimus-eluting stent (Abbott Vascular). The XIENCE 28 compared one-month DAPT with six-month DAPT. Whereas, the XIENCE 90 compared three-month DAPT with one-year DAPT. Both XIENCE 28 and XIENCE 90 demonstrated non-inferior of death or MI in the experimental group compared to the control group (XIENCE 28: 3.5\% versus. 4.3\%, P = 0.0005 for non-inferiority; XIENCE 90: 5.4\% versus $5.4 \%, \mathrm{P}=0.0063$ for non-inferiority). Major bleeding (BARC 3-5) was significantly reduced in the short DAPT arms of both trials (XIENCE 28: $2.2 \%$ versus $4.5 \%, \mathrm{P}=0.0156$ for superiority; XIENCE $90: 2.2 \%$ versus $6.3 \%, \mathrm{P}<$ 0.0001 for superiority). ${ }^{51}$

Regarding the current NSTE-ACS clinical practice guidelines, they recommend that ticagrelor monotherapy should be used after 3 months of a ticagrelor-based DAPT regimen for patients with low risk of bleeding. In cases of patients with a high risk of bleeding, a 3-month-DAPT regimen that combines aspirin and clopidogrel should be used, followed by single antiplatelet therapy with indefinite use of aspirin. Examples of high bleeding risk are patients scoring $\geq 25$ under PRECISE-DAPT (PREdicting bleeding Complications In patients undergoing Stent implantation and subsEquent Dual Anti Platelet Therapy), and patients meeting the relevant criteria of ARC-HBR (Academic Research Consortium High Bleeding Risk). For patients at very high risk of bleeding, a short 1-month DAPT regimen with aspirin and clopidogrel, followed by clopidogrel monotherapy, should be considered. ${ }^{9}$ A very high risk of bleeding is defined as a bleeding episode during the preceding month or surgery that cannot be deferred.

For patients with a high risk of ischemia, the duration of DAPT treatment could be prolonged. The PEGASUS TIMI (Prevention of Cardiovascular Events in Patients with Prior Heart Attack Using Ticagrelor Compared to Placebo on a Background of Aspirin-Thrombolysis in Myocardial Infarction) 54 trial demonstrated the benefits of ticagrelor over placebo in lowering ischemic endpoints in patients with a history of myocardial infarction for 1 to 3 years. In the trial, 21,162 prior myocardial infarction patients were randomly assigned in a 1:1:1 fashion to one of 3 treatment groups: $90 \mathrm{mg}$ of ticagrelor twice daily, $60 \mathrm{mg}$ of ticagrelor twice daily, and a placebo addition to low-dose aspirin. At both doses, ticagrelor reduced the rate of cardiovascular death, myocardial infarction, and stroke. Nevertheless, there was also an increased incidence of TIMI major bleeding. Moreover, the discontinuation rate of the 2 ticagrelor groups was significantly higher than that of the placebo group. ${ }^{52}$ In addition, the 60 -mg twice-daily dosage was better tolerated than the higher 90-mg twice-daily dosage: the lower dosage had a smaller incidence of bleeding and dyspnea.

The COMPASS (Cardiovascular Outcomes for People Using Anticoagulation Strategies) trial reported the benefits of very low-dose rivaroxaban with aspirin to prevent recurrence of a combined ischemic endpoint (a composite of cardiovascular death, stroke, and myocardial infarction). Patients had stable atherosclerotic vascular disease (coronary artery disease [CAD] or peripheral arterial disease), and the mean follow-up was 23 months. The trial randomly assigned 27,395 patients to 3 treatment groups: rivaroxaban $(2.5 \mathrm{mg}$, twice daily) plus aspirin (100 $\mathrm{mg}$, once daily); rivaroxaban alone ( $5 \mathrm{mg}$, twice daily); and aspirin alone (100 mg, once daily). Compared to aspirin monotherapy, the combination of rivaroxaban and aspirin reduced primary outcomes, but with an increased rate of major bleeding. A prespecified subgroup analysis focused on the high-risk subgroup. This group was defined as patients with polyvascular disease (at least 2 vascular beds affected by atherosclerosis), impaired renal function, heart failure, diabetes mellitus, or any combination of these conditions. The analysis demonstrated the net clinical benefits of the combination of very lowdose rivaroxaban and aspirin over aspirin monotherapy for the high-risk subgroup. ${ }^{53}$ The findings support the use of very low-dose rivaroxaban for this subgroup of patients.

The DAPT trial reported the benefits of prolonged DAPT (aspirin with clopidogrel or prasugrel) for 12 to 30 months after PCI. ${ }^{54}$ Compared to the standard 12-month DAPT regimen, the prolonged DAPT regimen significantly reduced the 
incidences of stent thrombosis and major adverse cardiovascular and cerebrovascular events. On the other hand, there was an increased risk of moderate or severe bleeding with the prolonged DAPT regimen.

The 2020 NSTE-ACS guidelines suggest extending long-term secondary prevention by adding a second antithrombotic agent (clopidogrel, prasugrel, ticagrelor, or rivaroxaban) to aspirin after 12 months of DAPT. This is specifically recommended for patients with moderate to high risk of ischemic events and without an increased risk of major or lifethreatening bleeding. The class of recommendation is IIa, and the level of evidence is A. ${ }^{9}$

For STEMI patients with high bleeding risks, the 2018 ESC/EACTS (European Association for Cardio-Thoracic Surgery) guidelines on myocardial revascularization suggest shortening the duration of DAPT (using clopidogrel or ticagrelor, with aspirin). Specifically, 6 months of DAPT is recommended in preference to the standard 12 months. ${ }^{55}$

\section{De-Escalation of the Potent Antiplatelet Therapies}

Another approach to reducing the rate of bleeding consequences is to de-escalate from the potent antiplatelet agent (prasugrel or ticagrelor) to clopidogrel. This is due to 2 factors. First, during the first 30 days after the start of treatment, it was observed that there was a significant reduction in the occurrence of ischemic events. ${ }^{12}$ Second, a significantly increased risk of bleeding with potent antiplatelet agents was found predominantly during the maintenance phase. ${ }^{56}$ Switching from a potent antiplatelet agent to clopidogrel (no sooner than 30 days after PCI) may therefore be a reasonable approach for patients who do not have a high risk of ischemia.

The TOPIC (Timing of Platelet Inhibition After Acute Coronary Syndrome) trial reported net clinical benefits of deescalating potent antiplatelet agents (43\% ticagrelor; 57\% prasugrel) to clopidogrel in patients with ACS (40\% STEMI) at their 1-month follow-up after PCI. ${ }^{57}$

The TROPICAL-ACS (Testing Responsiveness to Platelet Inhibition on Chronic Antiplatelet Treatment for Acute Coronary Syndromes) trial demonstrated the net clinical benefits of platelet function test (PFT)-guided de-escalation of prasugrel in biomarker-positive patients with ACS at their 1-year follow-up after PCI. Briefly, patients in the control group received prasugrel for 12 months. Regarding the patients in the guided de-escalation group, they received 1 week of prasugrel, followed by 1 week of clopidogrel, and then PFT-guided maintenance therapy. If PFT demonstrated clopidogrel high on-treatment platelet reactivity, the antiplatelet agent was switched from clopidogrel back to prasugrel, which was then maintained for 12 months. ${ }^{58}$

The 2020 NSTE-ACS guidelines state that for ACS patients who may be unsuitable for potent antiplatelet therapies, de-escalation of potent antiplatelet agents to clopidogrel can be considered as an alternative DAPT strategy. The deescalation can be based on clinical judgment and with or without a guided-PFT or genetic test. The class of recommendation is $\mathrm{IIb}$, and the level of evidence is $\mathrm{A}^{9}$

\section{Antiplatelet Therapy for ACS Patients Who are Managed Medically}

Although current clinical practice guidelines recommend an invasive approach for NSTE-ACS, in practice, approximately $35 \%$ of patients are only treated with medications. ${ }^{59}$

The TRILOGY-ACS (Targeted Platelet Inhibition to Clarify the Optimal Strategy to Medically Manage Acute Coronary Syndromes) trial enrolled 7243 medically managed NSTE-ACS patients aged under 75 years. The rates of primary endpoint and bleeding events of clopidogrel and prasugrel groups were similar. ${ }^{60}$ In a prespecified subgroup analysis of participants who underwent coronary angiography, prasugrel produced lower rates of cardiovascular death, myocardial infarction, and stroke than clopidogrel, with a similar rate for bleeding complications. ${ }^{61}$ This finding confirms that the benefits of prasugrel are limited to patients who have angiographically confirmed CAD.

The benefits of ticagrelor over clopidogrel were demonstrated by a prespecified subgroup analysis focusing on participants in the PLATO trial who were initially scheduled for non-invasive treatment (5216 of 18,624 patients). Ticagrelor showed reduced levels of combined ischemic endpoints with a similar rate of bleeding complications. ${ }^{62}$

The 2020 NSTE-ACS guidelines recommend the use of ticagrelor irrespective of the planned treatment strategy (invasive or conservative). The class of recommendation is I, and the level of evidence is B. In contrast, the guidelines recommend the use of prasugrel in $\mathrm{P}_{2} \mathrm{Y}_{12}$ receptor inhibitor-naive patients who are scheduled for PCI. The class of recommendation is I, and the level of evidence is $\mathrm{B} .{ }^{9}$ 
The 2016 ACC/AHA Guideline Focused Update on Duration of Dual Antiplatelet Therapy in Patients With Coronary Artery Disease recommends continuing DAPT (using clopidogrel or ticagrelor, with aspirin) for at least 12 months in patients with ACS who are managed with medical therapy. The class of recommendation is I, and the level of evidence is B. Furthermore, the guideline suggests that ticagrelor be used in preference to clopidogrel in this clinical setting. ${ }^{63}$ The class of recommendation is IIa, and the level of evidence is B.

For STEMI patients who receive thrombolytic agents and do not undergo PCI, the 2017 ESC Guidelines for the management of acute myocardial infarction in patients presenting with ST-segment elevation recommend the use of DAPT for 1 year. The class of recommendation is IIa, and the level of evidence is C. $^{10}$

\section{Antithrombotic Therapy for AF Patients Who Underwent PCI for ACS}

Patients with CAD commonly have concomitant atrial fibrillation (AF). ${ }^{64-66}$ The GRACE (Global Registry of Acute Coronary Events) study enrolled 59,032 patients Hospitalized with ACS. It found that approximately 10\% of patients with ACS had either pre-existing or newly developed AF upon admission. PCI was required in approximately $25 \%$ of the cases. ${ }^{67}$

After stent implantation, DAPT plays a vital role in preventing stent thrombosis ${ }^{68,69}$ and future recurrent MACE. ${ }^{70,71}$ In contrast, DAPT is not adequate for thromboembolic protection in patients with AF, who require anticoagulation therapy. ${ }^{72}$ Theoretically, triple antithrombotic therapy (TAT) that combines an oral anticoagulant (OAC) for thromboembolic prevention and DAPT for secondary prevention after PCI may be favorable for patients with AF who have undergone PCI. Still, evidence from major randomized controlled trials, ${ }^{73-76}$ recent meta-analyses,${ }^{77-80}$ and real-world data $^{81,82}$ shows that TAT is associated with a higher risk of severe bleeding than dual antithrombotic therapy (DAT) without significant benefits for ischemic endpoints.

The WOEST (What Is the Optimal Antiplatelet and Anticoagulant Therapy in Patients with Oral Anticoagulation and Coronary Stenting) trial ${ }^{83}$ compared the DAT regimens (clopidogrel plus VKA) to the TAT regimens (DAPT plus VKA) in patients who underwent PCI with indications of long-term anticoagulation therapy. The study identified that DAT decreased the rate of bleeding complications without increasing the number of thrombotic events.

Four pivotal randomized controlled trials studied the use of a direct oral anticoagulant (DOAC) in patients with AF who required PCI. The trials were PIONEER AF-PCI (Open-Label, Randomized, Controlled, Multicenter Study Exploring Two Treatment Strategies of Rivaroxaban and a Dose-Adjusted Oral Vitamin K Antagonist Treatment Strategy in Subjects with Atrial Fibrillation Who Undergo Percutaneous Coronary Intervention) ${ }^{73}$ RE-DUAL PCI (Randomized Evaluation of Dual Antithrombotic Therapy with Dabigatran versus Triple Therapy with Warfarin in Patients with Nonvalvular Atrial Fibrillation Undergoing Percutaneous Coronary Intervention) ${ }^{74}$ AUGUSTUS (Antithrombotic Therapy after Acute Coronary Syndrome or PCI in Atrial Fibrillation) trial ${ }^{75}$ and ENTRUST-AF PCI (Edoxaban Treatment Versus Vitamin K Antagonist in Patients with Atrial Fibrillation Undergoing Percutaneous Coronary Intervention) ${ }^{76}$ The primary endpoints of these landmark randomized controlled trials focused mainly on the safety endpoints of various definitions of bleeding complications. Based on the incidences of ischemic endpoints were relatively rare in these 4 trials. Therefore, underpower to assess the efficacy. ${ }^{84}$ Table 1 summarizes the main primary safety endpoints of the 4 trials.

In brief, the use of rivaroxaban $(20 \mathrm{mg})$, dabigatran $(110 \mathrm{mg})$, and apixaban $(5 \mathrm{mg})$ in DAT regimens caused lower bleeding endpoints than TAT with VKA and DAPT. At the same time, the use of dabigatran $(150 \mathrm{mg})$ and edoxaban $(60 \mathrm{mg})$ in the DAT regimens was not inferior to TAT in terms of bleeding complications. It should be noted that a regimen with a lower dosage of dabigatran $(110 \mathrm{mg}$, twice daily) reported a higher rate of myocardial infarction and stent thrombosis than TAT, but without statistical significance. As a result, the $2018 \mathrm{ESC} / \mathrm{EACTS}$ guidelines on myocardial revascularization recommend dabigatran $(150 \mathrm{mg}$, twice daily) when used in conjunction with aspirin or clopidogrel. ${ }^{55}$ A lower incidence of bleeding was associated with withdrawal of aspirin. ${ }^{75}$ However, a meta-analysis ${ }^{85}$ determined that DAT without aspirin was associated with a higher incidence of stent thrombosis and myocardial infarction. Consequently, the ischemic risk of each patient should be carefully assessed before removing aspirin from an antiplatelet regimen. 
Recent meta-analyses ${ }^{77-80}$ also concluded that the DAT regimen has fewer bleeding complications, including intracranial hemorrhage, than TAT. Furthermore, in terms of MACE, DAT was found to have an efficacy that was not significantly different from that of TAT. On the other hand, a meta-analysis reported a higher incidence of myocardial infarction and stent thrombosis with DAT. ${ }^{77}$ Therefore, the risks of ischemic and bleeding risks must be carefully weighed before beginning an antithrombotic regimen.

Table 2 summarizes the core recommendations of current clinical practice guidelines on the use of DOACs in patients with AF who had undergone PCI. ${ }^{9,55,84,86-88}$ The guidelines encourage the development of individualized antithrombotic regimens for patients after weighing their bleeding and ischemic risks, using validated risk scores. As a result, the duration of DAT and TAT depends on the clinical setting and the discretion of the treating physician. As for the default strategy, it is recommended that the antithrombotic regimen start with a brief period of TAT with DOAC and DAPT. Ideally, this would be $\leq 1$ week of TAT if a patient is not at high risk of stent thrombosis, with low-dose aspirin $(\leq$ $100 \mathrm{mg}$ /day). Then, DAT is applied. For this, the use of a DOAC (at the recommended dose for thromboembolic prevention) and clopidogrel for up to 12 months is recommended. For patients with a high risk of bleeding, the duration of DAT should be reduced to 6 months. After completion of the DAT regimen, the guidelines recommend the use of DOAC monotherapy.

The recommendations on extending the use of a DOAC beyond 1 year after PCI were derived from the trial evidence of AFIRE (Atrial Fibrillation and Ischemic Events with Rivaroxaban in Patients with Stable Coronary Artery Disease). ${ }^{89}$ The AFIRE study included 2236 patients who underwent PCI or coronary artery bypass graft (CABG) at least 1 year before their enrollment, as well as patients with CAD documented by coronary angiography that did not require revascularization. Participants received either rivaroxaban monotherapy or rivaroxaban with a single antiplatelet agent. The rivaroxaban monotherapy was found to be superior to the combination therapy in terms of the primary safety outcomes, with non-inferiority for the primary efficacy composite endpoints.

For VKA users, the guidelines aim to achieve the lower end of the international normalized ratio (2.0-2.5) with a high quality of time in the therapeutic range ( $\geq 65-70 \%)$.

The guidelines recommend the radial artery approach to reduce bleeding complications at the puncture site. Regarding the high incidence of gastrointestinal bleeding in patients using a DOAC, ${ }^{90}$ the guidelines encourage the routine use of proton pump inhibitors.

For STEMI patients who underwent primary PCI, the 2017 ESC guidelines for the treatment of acute myocardial infarction in patients with ST-segment elevation recommend an antithrombotic regimen for patients indicated for longterm DOAC use. In detail, the regimen is TAT for 6 months (or 3 months if there is a high risk of bleeding), followed by DAT until 12 months, and then DOAC monotherapy after the 1-year period. ${ }^{10}$

\section{Antithrombotic Therapy for AF Patients with ACS Who are Managed Medically}

Evidence from registry data of patients with AF who were treated medically for ACS was consistent with the results of a randomized controlled trial. There was a registry that included 12,165 patients with AF who had been hospitalized for ACS. Approximately $77 \%$ of the cases were treated medically. At the 1-year follow-up, there were no statistically significant differences in the incidences of recurrent coronary events and bleeding complications for DAT with OAC and clopidogrel, and for TAT with OAC and DAPT. ${ }^{81}$

Data from a prespecified subgroup analysis of medically managed patients of the AUGUSTUS trial (23\% of the enrolled population) demonstrated that DAT with edoxaban and $\mathrm{P}_{2} \mathrm{Y}_{12}$ inhibitors (mainly clopidogrel) resulted in fewer bleeding complications and a lower risk of death or hospitalization. However, the ischemic outcomes of TAT were similar to those of VKA and DAPT. ${ }^{91}$

The 2020 NSTE-ACS guidelines suggest the use of DAT with a DOAC and a single antiplatelet agent (preferably clopidogrel) for up to 1 year in patients who are managed medically. The class of recommendation is IIa, and the level of evidence is $\mathrm{C} .{ }^{9}$ 
Table I Major Randomized Controlled Trials on the Use of DOACs for NVAF Patients Who Underwent PCI

\begin{tabular}{|c|c|c|c|c|c|c|c|}
\hline $\begin{array}{l}\text { Study } \\
\text { Acronym }\end{array}$ & $\begin{array}{c}\text { Year of } \\
\text { Publication }\end{array}$ & $\begin{array}{l}\text { Main Inclusion } \\
\text { Criteria }\end{array}$ & $\begin{array}{c}\text { Number } \\
\text { of } \\
\text { Subjects }\end{array}$ & Treatment & $\begin{array}{c}\text { Mean } \\
\text { Follow- } \\
\text { Up } \\
\text { (Months) }\end{array}$ & $\begin{array}{c}\text { Primary } \\
\text { Safety } \\
\text { Outcomes }\end{array}$ & $\begin{array}{c}\text { Key Findings of Safety } \\
\text { Outcomes }\end{array}$ \\
\hline $\begin{array}{l}\text { PIONEER AF- } \\
\mathrm{PCl}^{73}\end{array}$ & 2016 & $\begin{array}{l}\text { NVAF who had } \\
\text { undergone PCI } \\
\text { - Stable CAD } 61.5 \% \\
\text { - ACS } 38.5 \%\end{array}$ & 2124 & $\begin{array}{l}\text { Randomized, open-label trial with I:I:I ratio. } \\
\text { - Group I } \\
\text { DAT with low-dose rivaroxaban ( } 15 \mathrm{mg} \text { once daily/ } 10 \mathrm{mg} \text { once } \\
\text { daily if moderate renal impairment) plus a } \mathrm{P}^{2} \mathrm{Y}_{\mathrm{I} 2} \text { inhibitor } \\
\text { - Group } 2 \\
\text { DAT with very-low-dose rivaroxaban ( } 2.5 \mathrm{mg} \text { twice daily) plus } \\
\text { DAPT for I, 6, or } 12 \text { months } \\
\text { - Group } 3 \text { TAT } \\
\text { TAT with VKA (INR 2.0-3.0) plus DAPT for I, 6, or } 12 \text { months }\end{array}$ & 12 & $\begin{array}{l}\text { CRNM } \\
\text { bleeding }\end{array}$ & $\begin{array}{l}\text { The risk of bleeding was } \\
\text { significantly lower in group I and } \\
\text { group } 2 \text { compared with group } 3 \text {. } \\
\text { - Group I VS group } 3 \\
\text { o I6.8\% VS } 26.7 \% \\
\text { o HR } 0.59 ; 95 \% \mathrm{Cl}, 0.47 \text { to } 0.76 \text {; } \\
\text { P }<0.00 \text { I for superiority. } \\
\text { - Group } 2 \text { VS group } 3 \\
\circ \text { I } 8.0 \% \text { VS } 26.7 \% \\
\circ \mathrm{HR} 0.63 ; 95 \% \mathrm{Cl}, 0.50 \text { to } 0.80 \text {; } \\
\mathrm{P}<0.00 \text { I for superiority. }\end{array}$ \\
\hline $\begin{array}{l}\text { RE-DUAL } \\
\mathrm{PCl}^{74}\end{array}$ & 2017 & $\begin{array}{l}\text { NVAF who had } \\
\text { undergone PCl } \\
\text { - Stable CAD } 49.5 \% \\
\text { - ACS } 51.5 \%\end{array}$ & 2725 & 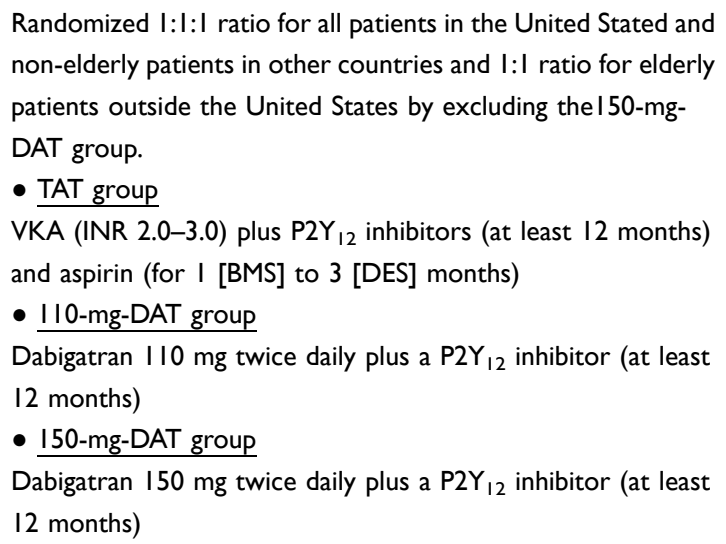 & 14 & $\begin{array}{c}\text { Major ISTH } \\
\text { or CRNM- } \\
\text { defined } \\
\text { bleeding }\end{array}$ & 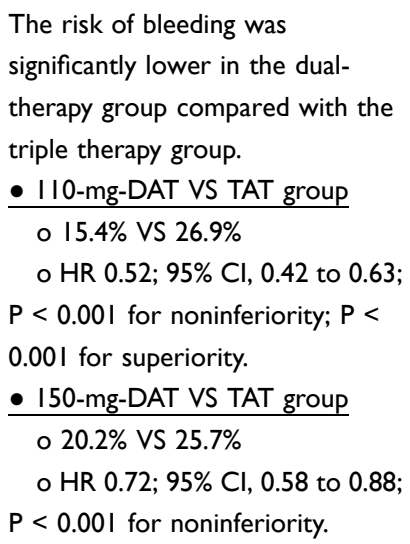 \\
\hline
\end{tabular}




\begin{tabular}{|c|c|c|c|c|c|c|c|}
\hline AUGUSTUS ${ }^{75}$ & 2019 & $\begin{array}{l}\text { NVAF who had } \\
\text { - Underwent PCI } \\
\text { o Stable CAD } \\
38.8 \% \\
\text { ○ ACS } 37.3 \% \\
\text { - Medically managed } \\
\text { ACS } 23.9 \%\end{array}$ & 4614 & $\begin{array}{l}\text { Two-by-two factorial design } \\
\text { - Open-label period } \\
\text { o Apixaban } 5 \mathrm{mg} \text { twice daily. (2.5 mg twice daily in selected } \\
\text { patient) } \\
\text { o VKA (INR 2.0-3.0) } \\
\text { - Double-blind period } \\
\text { O Aspirin } 100 \mathrm{mg} \text { daily } \\
\text { ○ Placebo }\end{array}$ & 6 & $\begin{array}{l}\text { Major ISTH } \\
\text { or CRNM- } \\
\text { defined } \\
\text { bleeding }\end{array}$ & $\begin{array}{l}\text { The risk of bleeding was } \\
\text { significantly lower for the patient } \\
\text { receiving apixaban as compared } \\
\text { with the VKA regimen. } \\
\text { - } 10.5 \% \text { VS } 14.7 \% \\
\text { - HR, } 0.69 ; 95 \% \mathrm{Cl}, 0.58 \text { to } 0.81 \text {; } \\
\text { P< } 0.00 \text { for both noninferiority } \\
\text { and superiority. } \\
\text { The risk of bleeding was } \\
\text { significantly higher for the patient } \\
\text { receiving aspirin compared to } \\
\text { placebo. } \\
\text { - } 16.1 \% \text { VS } 9.0 \% \\
\text { - HR, I.89; } 95 \% \mathrm{Cl}, 1.59 \text { to } 2.24 \text {; } \\
\text { P< } 0.00 \mathrm{I} \text {. }\end{array}$ \\
\hline $\begin{array}{l}\text { ENTRUST } \\
\text { AF-PCl }\end{array}$ & 2019 & $\begin{array}{l}\text { NVAF who had } \\
\text { undergone PCl } \\
\text { - Stable CAD } 48 \% \\
\text { - ACS } 52 \%\end{array}$ & 1506 & $\begin{array}{l}\text { Randomized, open-label, non-inferiority trial with I:I ratio. } \\
\text { - DAT group } \\
\text { Edoxaban } 60 \mathrm{mg} \text { once daily ( } 30 \mathrm{mg} \text { once daily if moderate } \\
\text { renal impairment) plus } \mathrm{P}_{12} \text { inhibitor (clopidogrel// prasugrel/ } \\
\text { ticagrelor) for } 12 \text { months. } \\
\text { - TAT group } \\
\text { VKA with a P2Y } Y_{12} \text { inhibitor (clopidogrel// prasugrel// ticagrelor) } \\
\text { and aspirin for I- } 12 \text { months }\end{array}$ & 12 & $\begin{array}{l}\text { Major ISTH } \\
\text { or CRNM- } \\
\text { defined } \\
\text { bleeding }\end{array}$ & $\begin{array}{l}\text { The DAT group was non-inferior } \\
\text { for the risk of bleeding compared } \\
\text { with the TAT group. } \\
\text { - } 17 \% \text { VS } 20.7 \% \\
\text { - HR, } 0.83 ; 95 \% \mathrm{Cl}, 0.65-1.05 ; \mathrm{P}= \\
0.0010 \text { for noninferiority. } \\
\text { - HR, I.20; P = } 0.1154 \text { for } \\
\text { superiority. }\end{array}$ \\
\hline
\end{tabular}

Abbreviations: 95\% Cl, 95\% confidence interval; ACS, acute coronary syndrome; AUGUSTUS, Antithrombotic Therapy after Acute Coronary Syndrome or PCl in Atrial Fibrillation; BMS, bare-metal stent; CAD, coronary artery disease; CRNM, clinically relevant non-major bleeding; DAPT, dual antiplatelet therapy; DAT, dual antithrombotic therapy; DES, drug-eluting stent; DOACs, direct oral anticoagulants; ENTRUST AF-PCI, Edoxaban Treatment Versus Vitamin K Antagonist in Patients with Atrial Fibrillation Undergoing Percutaneous Coronary Intervention; HR, hazard ratio; INR, international normalized ratio; ISTH, international society on thrombosis and hemostasis bleeding scale; NVAF, non-valvular atrial fibrillation; PCl, percutaneous coronary intervention; PIONEER AF-PCI, Open-Label, Randomized, Controlled, Multicenter Study Exploring Two Treatment Strategies of Rivaroxaban and a Dose-Adjusted Oral Vitamin K Antagonist Treatment Strategy in Subjects with Atrial Fibrillation Who Undergo Percutaneous Coronary Intervention; RE-DUAL PCI, Randomized Evaluation of Dual Antithrombotic Therapy with Dabigatran versus Triple Therapy with Warfarin in Patients with Nonvalvular Atrial Fibrillation Undergoing Percutaneous Coronary Intervention; TAT, triple antithrombotic therapy; VKA, vitamin K antagonist. 
Table 2 Summary of Core Recommendations of the Clinical Practice Guidelines on the Use of DOACs in AF Patients Who Underwent PCI for ACS

\begin{tabular}{|c|c|}
\hline Guidelines & Core Recommendations \\
\hline 2018 ESC/EACTS guidelines on myocardial revascularization ${ }^{55}$ & 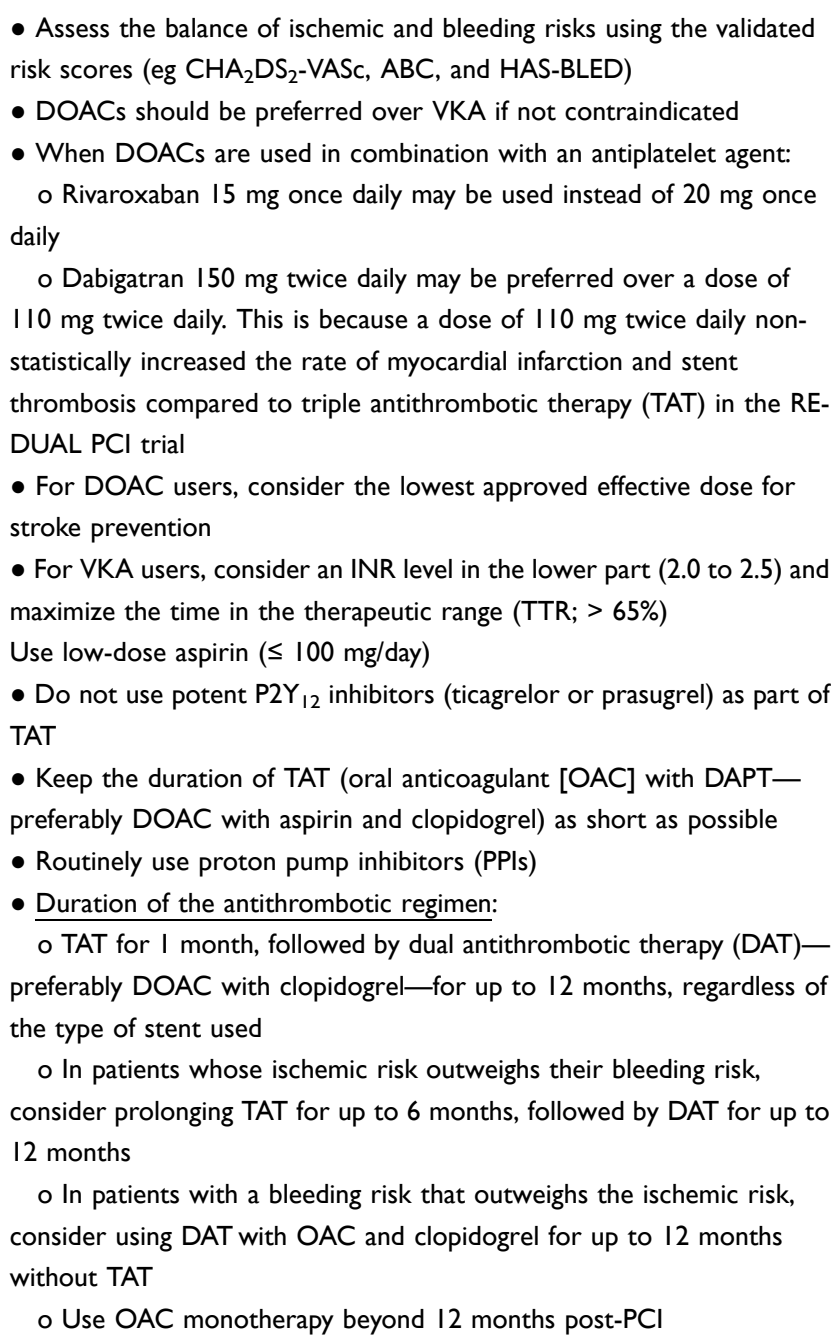 \\
\hline $\begin{array}{l}\text { The } 2018 \text { European heart rhythm association practical guide on the use } \\
\text { of non-vitamin } \mathrm{K} \text { antagonist oral anticoagulants in patients with atrial } \\
\text { fibrillation }^{86}\end{array}$ & $\begin{array}{l}\text { - Individualize the antithrombotic regimen approach for each patient } \\
\text { - Use new-generation drug-eluting stents (DES) to minimize the } \\
\text { duration of DAT or TAT } \\
\text { - Use a radial approach to reduce the risk of access site bleeding } \\
\text { - Duration of the antithrombotic regimen: } \\
\text { o ACS PCl } \\
\text { - TAT (DOAC, aspirin, and clopidogrel) for } 3 \text { months, followed by } \\
\text { DAT (DOAC with clopidogrel) for up to } 12 \text { months. Then, DOAC } \\
\text { monotherapy beyond } 12 \text { months post-PCI } \\
\text { - TAT (DOAC, aspirin, and ticagrelor) for I week or at discharge, } \\
\text { followed by DAT (DOAC with clopidogrel) for up to } 12 \text { months. DOAC } \\
\text { monotherapy beyond } 12 \text { months post-PCI }\end{array}$ \\
\hline $\begin{array}{l}2019 \mathrm{AHA} / \mathrm{ACC} / \mathrm{HRS} \text { focused update of the } 2014 \mathrm{AHA} / \mathrm{ACC} / \mathrm{HRS} \\
\text { guideline for the management of patients with atrial fibrillation } \\
\end{array}$ & $\begin{array}{l}\text { - In patients with } \mathrm{AF} \text { undergoing } \mathrm{PCl} \text { for } \mathrm{ACS} \text { with high bleeding risk, } \\
\text { DAT with a } \mathrm{P} \mathrm{Y}_{12} \text { inhibitor (preferably clopidogrel) and DOAC-low- } \\
\text { dose rivaroxaban } 15 \mathrm{mg} \text { daily or dabigatran } 150 \mathrm{mg} \text { twice daily-is } \\
\text { reasonable to reduce the risk of bleeding } \\
\text { - Consider de-escalating from TAT to DAT } 4 \text { to } 6 \text { weeks after PCl }\end{array}$ \\
\hline
\end{tabular}


Table 2 (Continued).

\begin{tabular}{|c|c|}
\hline Guidelines & Core Recommendations \\
\hline $\begin{array}{l}2020 \text { ESC guidelines for the management of acute coronary syndromes } \\
\text { in patients presenting without persistent ST-segment elevation }\end{array}$ & $\begin{array}{l}\text { - Duration of antithrombotic regimen for patients with AF undergoing } \\
\text { PCI for NSTE-ACS } \\
\text { o For the default strategy: } \\
\text { - Start with a short period of TAT (up to I week) with DOAC at } \\
\text { the recommended dose for stroke prevention and DAPT } \\
\text { - Then, use DAT with a DOAC and single antiplatelet therapy } \\
\text { (SAPT; preferably clopidogrel) for up to } 12 \text { months } \\
\text { - Beyond I } 2 \text { months after stenting, use a DOAC monotherapy } \\
\text { o In patients with a high risk of bleeding, antiplatelet therapy should be } \\
\text { withdrawn after } 6 \text { months } \\
\text { o Use of TAT should be prolonged for up to I month in patients with } \\
\text { a high ischemic risk, followed by DAT for up to } 12 \text { months }\end{array}$ \\
\hline $\begin{array}{l}2021 \text { European heart rhythm association practical guide on the use of } \\
\text { non-vitamin } \mathrm{K} \text { antagonist oral anticoagulants in patients with atrial } \\
\text { fibrillation }^{84}\end{array}$ & $\begin{array}{l}\text { - The choice of anticoagulant and the duration of the antithrombotic } \\
\text { regimen should be individualized and based on ischemic and bleeding } \\
\text { risks } \\
\text { - The use of established risk scoring systems (eg, CHA2DS2-VASc, } \\
\text { GRACE) to assess atherothrombotic risk is strongly recommended } \\
\text { - DOAC dosing should follow published and approved criteria } \\
\text { - The use of the individual DOAC's dose-reduction criteria is } \\
\text { recommended } \\
\text { PPIs should be used in all patients } \\
\text { - Duration of the antithrombotic regimen } \\
\text { o A short course of TAT for up to I week is recommended for all } \\
\text { patients with AF undergoing PCl } \\
\text { o For patients with a high risk of atherothrombotic risk, consider } \\
\text { prolonging TAT for up to } 30 \text { days }\end{array}$ \\
\hline
\end{tabular}

Abbreviations: ABC, age, biomarkers, clinical history; ACC, American College of Cardiology; ACS, acute coronary syndrome; AF, atrial fibrillation; AHA, American Heart Association; CHA2DS2-VASc, cardiac congestive heart failure, hypertension, age $\geq 75$ [doubled], diabetes mellitus, prior stroke or transient ischemic attack or thromboembolism [doubled], vascular disease, age 65-74 and sex category [female]; DAPT, dual antiplatelet therapy; DAT, dual antithrombotic therapy; DES, drug-eluting stents; DOACs, direct oral anticoagulants; EACTS, European Association for Cardio-Thoracic Surgery; ESC, European Society of Cardiology; GRACE, Global Registry of Acute Coronary Events; HAS-BLED, hypertension, abnormal renal/liver function, stroke, bleeding history or predisposition, labile INR, elderly, drugs/alcohol concomitantly; HRS, Heart Rhythm Society; INR, international normalized ratio; NSTE-ACS, non-ST-segment elevation acute coronary syndrome; OAC, oral anticoagulant; PCI, percutaneous coronary intervention; PPIs, proton pump inhibitors; RE-DUAL PCI, Randomized Evaluation of Dual Antithrombotic Therapy with Dabigatran versus Triple Therapy with Warfarin in Patients with Nonvalvular Atrial Fibrillation Undergoing Percutaneous Coronary Intervention; SAPT, single antiplatelet therapy; TAT, triple antithrombotic therapy; TTR, time in therapeutic range; VKA, vitamin $\mathrm{K}$ antagonist.

\section{Balance Between Ischemic and Bleeding Risks}

Bleeding complications affect adverse clinical outcomes, including short- and long-term mortality. ${ }^{8,92,93}$ A clinical risk scoring system has been established to help clinical decision-making on the duration of DAPT.

The PRECISE-DAPT risk calculator assesses 5 parameters: age, creatinine clearance, hemoglobin, white blood cell count, and previous spontaneous bleeding. For patients at high risk of bleeding (a PRECISE-DAPT score $\geq 25$ ), prolonged duration of DAPT was associated with bleeding complications. In comparison, for patients with low bleeding risk (a PRECISE-DAPT score $<25$ ), prolonged duration of DAPT improved the ischemic benefits of DAPT. ${ }^{94}$

The DAPT Score, which ranges from -2 to 10 , is calculated 1 year after PCI for ACS. Among patients with a high DAPT score ( $\geq 2$ ), prolonging DAPT for more than 12 months has been found to be associated with a reduction in the ischemic endpoint. In contrast, prolonging DAPT in patients with a lower DAPT score $(<2)$ was found to cause increased bleeding complications. ${ }^{95}$

Table 3 summarizes the strategies aimed at reducing bleeding complications. 
Table 3 Summary of Strategies to Reduce the Probability of Bleeding Complications

\begin{tabular}{|c|c|}
\hline Populations & Strategies \\
\hline $\begin{array}{l}\text { For all antithrombotic } \\
\text { users }\end{array}$ & $\begin{array}{l}\text { - Weigh the ischemic and bleeding risks using validated risk scoring systems to determine the appropriate antithrombotic } \\
\text { regimen and duration } \\
\text { - For the DAT regimen (OAC with antiplatelet): } \\
\text { o For the OAC, a DOAC is preferred over VKA } \\
\text { o For antiplatelet agents, P } 2 \text { Y I } 2 \text { inhibitors (preferably clopidogrel) are preferred to aspirin } \\
\text { - When using the TAT regimen (OAC with DAPT): } \\
\text { o Use the TAT regimen for as short a period as possible } \\
\text { o Do not use potent antiplatelet agents as part of the TAT regimen } \\
\text { o For the OAC, a DOAC is preferred over VKA } \\
\text { o For DAPT, the combination of clopidogrel and aspirin is preferred } \\
\text { - Use a radial approach if necessary for PCl to reduce puncture site bleeding }\end{array}$ \\
\hline For prasugrel users & $\begin{array}{l}\text { - Strictly use prasugrel in selected populations that meet the approved criteria } \\
\text { o Reduce prasugrel to } 5 \mathrm{mg} \text { per day in patients older than } 75 \text { years or whose body weight is below } 60 \mathrm{~kg} \\
\text { o Do not use prasugrel for patients with a previous stroke or TIA } \\
\text { - Use prasugrel only when the coronary artery is already documented and } \mathrm{PCl} \text { is planned }\end{array}$ \\
\hline For ticagrelor users & $\begin{array}{l}\text { - Use low-dose aspirin ( } \leq 100 \mathrm{mg} \text { per day) when concurrently used with ticagrelor or a DOAC } \\
\text { - Concomitant use of ticagrelor and DOACs only in patients at high risk of ischemia and without a significant risk of } \\
\text { bleeding }\end{array}$ \\
\hline For DOACs users & $\begin{array}{l}\text { - Use the individual DOAC's dose-reduction criteria } \\
\text { - Routinely use PPIs with DOACs }\end{array}$ \\
\hline For VKA users & - When VKA is involved in an antithrombotic regimen, aim for a target INR range of 2.0 to 2.5 \\
\hline
\end{tabular}

Abbreviations: DAPT, dual antiplatelet therapy; DAT, dual antithrombotic therapy; DOACs, direct anticoagulants; INR, international normalized ratio; PCI, percutaneous coronary intervention; PPIs, proton pump inhibitors; SAPT, single antiplatelet therapy; TAT, triple antithrombotic therapy; TIA, transient ischemic attack; TTR, time in therapeutic range; VKA, vitamin $\mathrm{K}$ antagonist.

\section{Conclusion}

Treatment paradigms regarding the antithrombotic strategy after ACS are evolving from the generalized approach toward the individualized approach for maximizing the ischemic protection and minimizing the bleeding complications individually. As a result, individual bleeding and ischemic risks should be carefully explored to justify the appropriate antithrombotic strategy, including the choice of antithrombotic agents and the duration of the regimen. To date, various risk scoring systems based on the ischemic and bleeding risk have been established for aiding clinicians' discretion to arrange the appropriated "tailor" antithrombotic treatment plan.

\section{Acknowledgments}

We gratefully acknowledge the professional editing of this paper by Mr. David Park.

\section{Disclosure}

The authors report that there are no conflicts of interest related to this work.

\section{References}

1. Vedanthan R, Seligman B, Fuster V. Global perspective on acute coronary syndrome: a burden on the young and poor. Circ Res. 2014;114 (12):1959-1975. doi:10.1161/CIRCRESAHA.114.302782

2. Sanchis-Gomar F, Perez-Quilis C, Leischik R, Lucia A. Epidemiology of coronary heart disease and acute coronary syndrome. Ann Transl Med. 2016;4(13):256. doi:10.21037/atm.2016.06.33

3. Ralapanawa U, Sivakanesan R. Epidemiology and the magnitude of coronary artery disease and acute coronary syndrome: a narrative review. J Epidemiol Glob Health. 2021;11(2):169-177. doi:10.2991/jegh.k.201217.001 
4. Yudi MB, Clark DJ, Farouque O, et al. Trends and predictors of recurrent acute coronary syndrome hospitalizations and unplanned revascularization after index acute myocardial infarction treated with percutaneous coronary intervention. Am Heart J. 2019;212:134-143. doi:10.1016/j. ahj.2019.02.013

5. Hammer Y, Iakobishvili Z, Hasdai D, et al. Guideline-recommended therapies and clinical outcomes according to the risk for recurrent cardiovascular events after an acute coronary syndrome. J Am Heart Assoc. 2018;7(18):e009885. doi:10.1161/JAHA.118.009885

6. Kolansky DM. Acute coronary syndromes: morbidity, mortality, and pharmacoeconomic burden. Am J Manag Care. 2009;15(2Suppl):S36-41.

7. Chan Pin Yin D, Ten Berg JM. Long-term residual cardiovascular risk after acute coronary syndrome: antithrombotic treatment options. Neth Heart J. 2021;30:38-46. doi:10.1007/s12471-021-01604-4

8. Steg PG, Huber K, Andreotti F, et al. Bleeding in acute coronary syndromes and percutaneous coronary interventions: position paper by the Working Group on Thrombosis of the European Society of Cardiology. Eur Heart J. 2011;32(15):1854-1864. doi:10.1093/eurheartj/ehr204

9. Collet JP, Thiele H, Barbato E, et al. 2020 ESC guidelines for the management of acute coronary syndromes in patients presenting without persistent ST-segment elevation. Eur Heart J. 2021;42(14):1289-1367. doi:10.1093/eurheartj/ehaa575

10. Ibanez B, James S, Agewall S, et al. 2017 ESC guidelines for the management of acute myocardial infarction in patients presenting with ST-segment elevation: the task force for the management of acute myocardial infarction in patients presenting with ST-segment elevation of the European Society of Cardiology (ESC). Eur Heart J. 2018;39(2):119-177. doi:10.1093/eurheartj/ehx393

11. Wallentin L, Becker RC, Budaj A, et al. Ticagrelor versus clopidogrel in patients with acute coronary syndromes. $N$ Engl $J$ Med. 2009;361 (11):1045-1057. doi:10.1056/NEJMoa0904327

12. Wiviott SD, Braunwald E, McCabe CH, et al. Prasugrel versus clopidogrel in patients with acute coronary syndromes. $N$ Engl $J$ Med. $2007 ; 357$ (20):2001-2015. doi:10.1056/NEJMoa0706482

13. Alexopoulos D, Xanthopoulou I, Deftereos S, et al. Contemporary antiplatelet treatment in acute coronary syndrome patients undergoing percutaneous coronary intervention: 1-year outcomes from the Greek AntiPlatElet (GRAPE) registry. J Thromb Haemost. 2016;14 (6):1146-1154. doi: $10.1111 /$ jth. 13316

14. Fox KA, Mehta SR, Peters R, et al. Benefits and risks of the combination of clopidogrel and aspirin in patients undergoing surgical revascularization for non-ST-elevation acute coronary syndrome: the Clopidogrel in Unstable angina to prevent Recurrent ischemic Events (CURE) trial. Circulation. 2004;110(10):1202-1208. doi:10.1161/01.CIR.0000140675.85342.1B

15. Wiviott SD, Antman EM, Braunwald E. Prasugrel. Circulation. 2010;122(4):394-403. doi:10.1161/CIRCULATIONAHA.109.921502

16. Wiviott SD, Trenk D, Frelinger AL, et al. Prasugrel compared with high loading- and maintenance-dose clopidogrel in patients with planned percutaneous coronary intervention: the Prasugrel in comparison to clopidogrel for inhibition of platelet activation and aggregation-thrombolysis in myocardial infarction 44 trial. Circulation. 2007;116(25):2923-2932. doi:10.1161/CIRCULATIONAHA.107.740324

17. Buonamici P, Marcucci R, Migliorini A, et al. Impact of platelet reactivity after clopidogrel administration on drug-eluting stent thrombosis. $J$ Am Coll Cardiol. 2007;49(24):2312-2317. doi:10.1016/j.jacc.2007.01.094

18. Simon T, Verstuyft C, Mary-Krause M, et al. Genetic determinants of response to clopidogrel and cardiovascular events. $N$ Engl $J$ Med. 2009;360 (4):363-375. doi:10.1056/NEJMoa0808227

19. Gurbel PA, Bliden KP, Samara W, et al. Clopidogrel effect on platelet reactivity in patients with stent thrombosis: results of the CREST study. $J$ Am Coll Cardiol. 2005;46(10):1827-1832. doi:10.1016/j.jacc.2005.07.056

20. Geisler T, Langer H, Wydymus M, et al. Low response to clopidogrel is associated with cardiovascular outcome after coronary stent implantation. Eur Heart J. 2006;27(20):2420-2425. doi:10.1093/eurheartj/ehl275

21. Pereira NL, Farkouh ME, So D, et al. Effect of genotype-guided oral P2Y12 inhibitor selection vs conventional clopidogrel therapy on ischemic outcomes after percutaneous coronary intervention: the TAILOR-PCI randomized clinical trial. JAMA. 2020;324(8):761-771. doi:10.1001/ jama.2020.12443

22. Amsterdam EA, Wenger NK, Brindis RG, et al. 2014 AHA/ACC guideline for the management of patients with non-ST-elevation acute coronary syndromes: a report of the American College of Cardiology/American Heart Association Task Force on practice guidelines. $J$ Am Coll Cardiol. 2014;64(24):e139-e228. doi:10.1016/j.jacc.2014.09.017

23. Mehta SR, Bassand JP, Chrolavicius S, et al.; OASIS C. Dose comparisons of clopidogrel and aspirin in acute coronary syndromes. $N$ Engl J Med. 2010;363(10):930-942. doi:10.1056/NEJMoa0909475

24. Mehta SR, Tanguay JF, Eikelboom JW, et al. Double-dose versus standard-dose clopidogrel and high-dose versus low-dose aspirin in individuals undergoing percutaneous coronary intervention for acute coronary syndromes (CURRENT-OASIS 7): a randomised factorial trial. Lancet. 2010;376(9748):1233-1243. doi:10.1016/S0140-6736(10)61088-4

25. Wallentin L, Varenhorst C, James S, et al. Prasugrel achieves greater and faster P2Y12receptor-mediated platelet inhibition than clopidogrel due to more efficient generation of its active metabolite in aspirin-treated patients with coronary artery disease. Eur Heart J. 2008;29(1):21-30. doi:10.1093/eurheartj/ehm545

26. Gurbel PA, Bliden KP, Butler K, et al. Randomized double-blind assessment of the ONSET and OFFSET of the antiplatelet effects of ticagrelor versus clopidogrel in patients with stable coronary artery disease: the ONSET/OFFSET study. Circulation. 2009;120(25):2577-2585. doi:10.1161/ CIRCULATIONAHA.109.912550

27. Angiolillo DJ, Franchi F, Waksman R, et al. Effects of ticagrelor versus clopidogrel in troponin-negative patients with low-risk ACS undergoing ad hoc PCI. J Am Coll Cardiol. 2016;67(6):603-613. doi:10.1016/j.jacc.2015.11.044

28. Chen Y, Dong W, Wan Z, et al. Ticagrelor versus clopidogrel in Chinese patients with acute coronary syndrome: a pharmacodynamic analysis. Int J Cardiol. 2015;201:545-546. doi:10.1016/j.ijcard.2015.06.030

29. Wiviott SD, Braunwald $\mathrm{E}, \mathrm{McCabe} \mathrm{CH}$, et al. Intensive oral antiplatelet therapy for reduction of ischaemic events including stent thrombosis in patients with acute coronary syndromes treated with percutaneous coronary intervention and stenting in the TRITON-TIMI 38 trial: a subanalysis of a randomised trial. Lancet. 2008;371(9621):1353-1363. doi:10.1016/S0140-6736(08)60422-5

30. Morrow DA, Wiviott SD, White HD, et al. Effect of the novel thienopyridine prasugrel compared with clopidogrel on spontaneous and procedural myocardial infarction in the trial to assess improvement in therapeutic outcomes by optimizing platelet inhibition with prasugrel-thrombolysis in myocardial infarction 38: an application of the classification system from the universal definition of myocardial infarction. Circulation. 2009;119 (21):2758-2764. doi:10.1161/CIRCULATIONAHA.108.833665 
31. Murphy SA, Antman EM, Wiviott SD, et al. Reduction in recurrent cardiovascular events with prasugrel compared with clopidogrel in patients with acute coronary syndromes from the TRITON-TIMI 38 trial. Eur Heart J. 2008;29(20):2473-2479. doi:10.1093/eurheartj/ehn362

32. Wiviott SD, Desai N, Murphy SA, et al. Efficacy and safety of intensive antiplatelet therapy with prasugrel from TRITON-TIMI 38 in a core clinical cohort defined by worldwide regulatory agencies. Am J Cardiol. 2011;108(7):905-911. doi:10.1016/j.amjcard.2011.05.020

33. De Servi S, Goedicke J, Schirmer A, Widimsky P. Clinical outcomes for prasugrel versus clopidogrel in patients with unstable angina or non-STelevation myocardial infarction: an analysis from the TRITON-TIMI 38 trial. Eur Heart J Acute Cardiovasc Care. 2014;3(4):363-372. doi:10.1177/ 2048872614534078

34. Steg PG, Harrington RA, Emanuelsson H, et al. Stent thrombosis with ticagrelor versus clopidogrel in patients with acute coronary syndromes: an analysis from the prospective, randomized PLATO trial. Circulation. 2013;128(10):1055-1065. doi:10.1161/CIRCULATIONAHA.113.002589

35. Nawarskas JJ, Snowden SS. Critical appraisal of ticagrelor in the management of acute coronary syndrome. Ther Clin Risk Manag. 2011;7:473-488. doi:10.2147/TCRM.S19835

36. Gimbel M, Qaderdan K, Willemsen L, et al. Clopidogrel versus ticagrelor or prasugrel in patients aged 70 years or older with non-ST-elevation acute coronary syndrome (POPular AGE): the randomised, open-label, non-inferiority trial. Lancet. 2020;395(10233):1374-1381. doi:10.1016/ S0140-6736(20)30325-1

37. Montalescot G, Collet JP, Ecollan P, et al. Effect of prasugrel pre-treatment strategy in patients undergoing percutaneous coronary intervention for NSTEMI: the ACCOAST-PCI study. J Am Coll Cardiol. 2014;64(24):2563-2571. doi:10.1016/j.jacc.2014.08.053

38. Montalescot G, Bolognese L, Dudek D, et al. Pretreatment with prasugrel in non-ST-segment elevation acute coronary syndromes. $N$ Engl $J$ Med. 2013;369(11):999-1010. doi:10.1056/NEJMoa1308075

39. Dworeck C, Redfors B, Angeras O, et al. Association of pretreatment with P2Y12 receptor antagonists preceding percutaneous coronary intervention in non-ST-segment elevation acute coronary syndromes with outcomes. JAMA Netw Open. 2020;3(10):e2018735. doi:10.1001/ jamanetworkopen.2020.18735

40. Motovska Z, Hlinomaz O, Miklik R, et al. Prasugrel versus ticagrelor in patients with acute myocardial infarction treated with primary percutaneous coronary intervention: multicenter randomized prague-18 study. Circulation. 2016;134(21):1603-1612. doi:10.1161/ CIRCULATIONAHA.116.024823

41. Olier I, Sirker A, Hildick-Smith DJR, et al. Association of different antiplatelet therapies with mortality after primary percutaneous coronary intervention. Heart. 2018;104(20):1683-1690. doi:10.1136/heartjnl-2017-312366

42. Schupke S, Neumann FJ, Menichelli M, et al. Ticagrelor or prasugrel in patients with acute coronary syndromes. $N$ Engl J Med. 2019;381 (16):1524-1534. doi:10.1056/NEJMoa1908973

43. Vranckx P, Valgimigli M, Juni P, et al. Ticagrelor plus aspirin for 1 month, followed by ticagrelor monotherapy for 23 months vs aspirin plus clopidogrel or ticagrelor for 12 months, followed by aspirin monotherapy for 12 months after implantation of a drug-eluting stent: a multicentre, open-label, randomised superiority trial. Lancet. 2018;392(10151):940-949. doi:10.1016/S0140-6736(18)31858-0

44. Mehran R, Baber U, Sharma SK, et al. Ticagrelor with or without aspirin in high-risk patients after PCI. N Engl J Med. 2019;381(21):2032-2042. doi:10.1056/NEJMoa1908419

45. Watanabe H, Domei T, Morimoto T, et al. Effect of 1-month dual antiplatelet therapy followed by clopidogrel vs 12-month dual antiplatelet therapy on cardiovascular and bleeding events in patients receiving PCI: the STOPDAPT-2 randomized clinical trial. JAMA. 2019;321(24):2414-2427. doi:10.1001/jama.2019.8145

46. Obayashi Y. Short and optimal duration of dual antiplatelet therapy after everolimus-eluting cobalt-chromium stent-2 acute coronary syndrome STOPDAPT-2 ACS. the Transcatheter Cardiovascular Therapeutics (TCT); November 5; 2021; Orlando, FL; 2021.

47. Hahn JY, Song YB, Oh JH, et al. 6-month versus 12-month or longer dual antiplatelet therapy after percutaneous coronary intervention in patients with acute coronary syndrome (SMART-DATE): a randomised, open-label, non-inferiority trial. Lancet. 2018;391(10127):1274-1284. doi:10.1016/ S0140-6736(18)30493-8

48. Windecker S, Latib A, Kedhi E, et al. Polymer-based or polymer-free stents in patients at high bleeding risk. $N$ Engl J Med. 2020;382 (13):1208-1218. doi:10.1056/NEJMoa1910021

49. Windecker S, Kedhi E, Latib A, et al. Final two-year results from the randomized Onyx One trial in high bleeding risk patients treated with 1-month DAPT. J Am Coll Cardiol. 2021;77(18):899. doi:10.1016/S0735-1097(21)02258-0

50. Valgimigli M, Frigoli E, Heg D, et al. Dual antiplatelet therapy after PCI in patients at high bleeding risk. N Engl J Med. 2021;385(18):1643-1655. doi:10.1056/NEJMoa2108749

51. Mehran R. The XIENCE short DAPT program: XIENCE 90/28 evaluating the safety of 3-month and 1-month DAPT in HBR patients. Presented at: TCT Connect 2020. October 16; 2020; virtual.

52. Bonaca MP, Bhatt DL, Cohen M, et al. Long-term use of ticagrelor in patients with prior myocardial infarction. $N$ Engl $J$ Med. 2015;372 (19):1791-1800. doi:10.1056/NEJMoa1500857

53. Steffel J, Eikelboom JW, Anand SS, Shestakovska O, Yusuf S, Fox KAA. The COMPASS trial: net clinical benefit of low-dose rivaroxaban plus aspirin as compared with aspirin in patients with chronic vascular disease. Circulation. 2020;142(1):40-48. doi:10.1161/ CIRCULATIONAHA.120.046048

54. Mauri L, Kereiakes DJ, Yeh RW, et al. Twelve or 30 months of dual antiplatelet therapy after drug-eluting stents. $N$ Engl J Med. 2014;371 (23):2155-2166. doi:10.1056/NEJMoa1409312

55. Neumann FJ, Sousa-Uva M, Ahlsson A, et al. 2018 ESC/EACTS guidelines on myocardial revascularization. Eur Heart J. 2019;40(2):87-165. doi:10.1093/eurheartj/ehy394

56. Antman EM, Wiviott SD, Murphy SA, et al. Early and late benefits of prasugrel in patients with acute coronary syndromes undergoing percutaneous coronary intervention: a TRITON-TIMI 38 (TRial to assess improvement in therapeutic outcomes by optimizing platelet inhibition with Prasugrel-thrombolysis in myocardial infarction) analysis. J Am Coll Cardiol. 2008;51(21):2028-2033. doi:10.1016/j.jacc.2008.04.002

57. Cuisset T, Deharo P, Quilici J, et al. Benefit of switching dual antiplatelet therapy after acute coronary syndrome: the TOPIC (timing of platelet inhibition after acute coronary syndrome) randomized study. Eur Heart J. 2017;38(41):3070-3078. doi:10.1093/eurheartj/ehx175

58. Sibbing D, Aradi D, Jacobshagen C, et al. Guided de-escalation of antiplatelet treatment in patients with acute coronary syndrome undergoing percutaneous coronary intervention (TROPICAL-ACS): a randomised, open-label, multicentre trial. Lancet. 2017;390(10104):1747-1757. doi:10.1016/S0140-6736(17)32155-4 
59. Valgimigli M. Pretreatment with P2Y12 inhibitors in non-ST-segment-elevation acute coronary syndrome is clinically justified. Circulation. 2014;130(21):1891-903; discussion 903. doi:10.1161/CIRCULATIONAHA.114.011319

60. Roe MT, Armstrong PW, Fox KA, et al. Prasugrel versus clopidogrel for acute coronary syndromes without revascularization. $N$ Engl $J$ Med. 2012;367(14):1297-1309. doi:10.1056/NEJMoa1205512

61. Wiviott SD, White HD, Ohman EM, et al. Prasugrel versus clopidogrel for patients with unstable angina or non-ST-segment elevation myocardial infarction with or without angiography: a secondary, prespecified analysis of the TRILOGY ACS trial. Lancet. 2013;382(9892):605-613. doi:10.1016/S0140-6736(13)61451-8

62. James SK, Roe MT, Cannon CP, et al. Ticagrelor versus clopidogrel in patients with acute coronary syndromes intended for non-invasive management: substudy from prospective randomised PLATelet inhibition and patient Outcomes (PLATO) trial. BMJ. 2011;342:d3527. doi:10.1136/bmj.d3527

63. Levine GN, Bates ER, Bittl JA, et al. 2016 ACC/AHA guideline focused update on duration of dual antiplatelet therapy in patients with coronary artery disease: a report of the American College of Cardiology/American Heart Association Task Force on clinical practice guidelines: an update of the $2011 \mathrm{ACCF} / \mathrm{AHA} / \mathrm{SCAI}$ guideline for percutaneous coronary intervention, $2011 \mathrm{ACCF} / \mathrm{AHA}$ guideline for coronary artery bypass graft surgery, 2012 ACC/AHA/ACP/AATS/PCNA/SCAI/STS guideline for the diagnosis and management of patients with stable ischemic heart disease, 2013 ACCF/AHA guideline for the management of ST-elevation myocardial infarction, 2014 AHA/ACC guideline for the management of patients with non-ST-elevation acute coronary syndromes, and 2014 ACC/AHA guideline on perioperative cardiovascular evaluation and management of patients undergoing noncardiac surgery. Circulation. 2016;134(10):e123-55. doi:10.1161/CIR.0000000000000404

64. Akao M. Atrial fibrillation and coronary artery disease: resembling twins? J Cardiol. 2014;63(2):169-170. doi:10.1016/j.jjcc.2013.09.010

65. Michniewicz E, Mlodawska E, Lopatowska P, Tomaszuk-Kazberuk A, Malyszko J. Patients with atrial fibrillation and coronary artery disease Double trouble. Adv Med Sci. 2018;63(1):30-35. doi:10.1016/j.advms.2017.06.005

66. Liang F, Wang Y. Coronary heart disease and atrial fibrillation: a vicious cycle. Am J Physiol Heart Circ Physiol. 2021;320(1):H1-H12. doi:10.1152/ajpheart.00702.2020

67. McManus DD, Huang W, Domakonda KV, et al. Trends in atrial fibrillation in patients hospitalized with an acute coronary syndrome. Am J Med. 2012;125(11):1076-1084. doi:10.1016/j.amjmed.2012.05.024

68. Cho MS, Park DW. Stent thrombosis and optimal duration of dual antiplatelet therapy after coronary stenting in contemporary practice. Korean J Intern Med. 2017;32(5):769-779. doi:10.3904/kjim.2016.391

69. Camarero TG, de la Torre Hernandez JM. Antithrombotic treatment after coronary intervention: agreement and controversy. Eur Cardiol. 2020;15:1-8. doi:10.15420/ecr.2019.25.2

70. Grines CL, Bonow RO, Casey DE, et al. Prevention of premature discontinuation of dual antiplatelet therapy in patients with coronary artery stents: a science advisory from the American Heart Association, American College of Cardiology, Society for Cardiovascular Angiography and Interventions, American College of Surgeons, and American Dental Association, with representation from the American College of Physicians. Circulation. 2007;115(6):813-818. doi:10.1161/CIRCULATIONAHA.106.180944

71. Degrauwe S, Pilgrim T, Aminian A, Noble S, Meier P, Iglesias JF. Dual antiplatelet therapy for secondary prevention of coronary artery disease. Open Heart. 2017;4(2):e000651. doi:10.1136/openhrt-2017-000651

72. Site HG. Clopidogrel plus aspirin versus oral anticoagulation for atrial fibrillation in the Atrial fibrillation Clopidogrel Trial with Irbesartan for prevention of Vascular Events (ACTIVE W): a randomised controlled trial. Lancet. 2006;367(9526):1903-1912. doi:10.1016/S0140-6736(06) 68845-4

73. Gibson CM, Mehran R, Bode C, et al. Prevention of bleeding in patients with atrial fibrillation undergoing PCI. $N$ Engl J Med. 2016;375 (25):2423-2434. doi:10.1056/NEJMoa1611594

74. Cannon CP, Bhatt DL, Oldgren J, et al. Dual antithrombotic therapy with dabigatran after PCI in atrial fibrillation. $N$ Engl J Med. 2017;377 (16):1513-1524. doi:10.1056/NEJMoa1708454

75. Lopes RD, Heizer G, Aronson R, et al. Antithrombotic therapy after acute coronary syndrome or PCI in atrial fibrillation. N Engl J Med. 2019;380 (16):1509-1524. doi:10.1056/NEJMoa1817083

76. Vranckx P, Valgimigli M, Eckardt L, et al. Edoxaban-based versus vitamin K antagonist-based antithrombotic regimen after successful coronary stenting in patients with atrial fibrillation (ENTRUST-AF PCI): a randomised, open-label, phase 3b trial. Lancet. 2019;394(10206):1335-1343. doi:10.1016/S0140-6736(19)31872-0

77. Gargiulo G, Cannon CP, Gibson CM, et al. Safety and efficacy of double vs. triple antithrombotic therapy in patients with atrial fibrillation with or without acute coronary syndrome undergoing percutaneous coronary intervention: a collaborative meta-analysis of non-vitamin $\mathrm{K}$ antagonist oral anticoagulant-based randomized clinical trials. Eur Heart J Cardiovasc Pharmacother. 2021;7(FI1):f50-f60. doi:10.1093/ehjcvp/pvaa116

78. Goel S, Pasam RT, Sharma A, Gidwani U. Dual versus triple antithrombotic therapy after acute coronary syndrome or percutaneous coronary intervention in patients with atrial fibrillation: an updated meta-analysis. Cardiovasc Revasc Med. 2020;21(2):239-241. doi:10.1016/j. carrev.2019.08.015

79. Shin D, Mohanty BD, Lee ES. Dual versus triple antithrombotic therapy after percutaneous coronary intervention or acute coronary syndrome in patients with indication for anticoagulation: an updated meta-analysis. Coron Artery Dis. 2018;29(8):670-680. doi:10.1097/ MCA.0000000000000660

80. Shurrab M, Danon A, Alnasser S, et al. Dual-antithrombotic therapy with DOACs after acute coronary syndrome or percutaneous coronary intervention in atrial fibrillation: a meta-analysis of randomized controlled trials. Can J Cardiol. 2020;36(1):135-142. doi:10.1016/j. cjca.2019.11.005

81. Lamberts M, Gislason GH, Olesen JB, et al. Oral anticoagulation and antiplatelets in atrial fibrillation patients after myocardial infarction and coronary intervention. J Am Coll Cardiol. 2013;62(11):981-989. doi:10.1016/j.jacc.2013.05.029

82. Lamberts M, Olesen JB, Ruwald MH, et al. Bleeding after initiation of multiple antithrombotic drugs, including triple therapy, in atrial fibrillation patients following myocardial infarction and coronary intervention: a nationwide cohort study. Circulation. 2012;126(10):1185-1193. doi:10.1161/ CIRCULATIONAHA.112.114967

83. Dewilde WJ, Oirbans T, Verheugt FW, et al. Use of clopidogrel with or without aspirin in patients taking oral anticoagulant therapy and undergoing percutaneous coronary intervention: an open-label, randomised, controlled trial. Lancet. 2013;381(9872):1107-1115. doi:10.1016/S0140-6736(12) $62177-1$ 
84. Steffel J, Collins R, Antz M, et al. 2021 European heart rhythm association practical guide on the use of non-vitamin K antagonist oral anticoagulants in patients with atrial fibrillation. Europace. 2021. doi:10.1093/europace/euab065

85. Luo CF, Mo P, Li GQ, Liu SM. Aspirin-omitted dual antithrombotic therapy in non-valvular atrial fibrillation patients presenting with acute coronary syndrome or undergoing percutaneous coronary intervention: results of a meta-analysis. Eur Heart J Cardiovasc Pharmacother. 2021;7 (3):218-224. doi:10.1093/ehjcvp/pvaa016

86. Steffel J, Verhamme P, Potpara TS, et al. The 2018 European heart rhythm association practical guide on the use of non-vitamin K antagonist oral anticoagulants in patients with atrial fibrillation. Eur Heart J. 2018;39(16):1330-1393. doi:10.1093/eurheartj/ehy136

87. Knuuti J, Wijns W, Saraste A, et al. 2019 ESC Guidelines for the diagnosis and management of chronic coronary syndromes. Eur Heart J. 2020;41 (3):407-477. doi:10.1093/eurheartj/ehz425

88. January CT, Wann LS, Calkins H, et al. 2019 AHA/ACC/HRS focused update of the 2014 AHA/ACC/HRS guideline for the management of patients with atrial fibrillation: a report of the American College of Cardiology/American Heart Association Task Force on clinical practice guidelines and the heart rhythm society. $J$ Am Coll Cardiol. 2019;74(1):104-132. doi:10.1016/j.jacc.2019.01.011

89. Yasuda S, Kaikita K, Akao M, et al. Antithrombotic therapy for atrial fibrillation with stable coronary disease. $N$ Engl J Med. 2019;381 (12):1103-1113. doi:10.1056/NEJMoa1904143

90. Kwon S, Lee SR, Choi EK, et al. Non-vitamin K antagonist oral anticoagulants in patients with atrial fibrillation and prior gastrointestinal bleeding. Stroke. 2021;52(2):511-520. doi:10.1161/STROKEAHA.120.030761

91. Lopes RD, Hong H, Alexander JH. Antithrombotic therapy after acute coronary syndrome and/or percutaneous coronary intervention in atrial fibrillation: finding the sweet spot. Eur Heart J. 2019;40(46):3768-3770. doi:10.1093/eurheartj/ehz823

92. Chhatriwalla AK, Amin AP, Kennedy KF, et al. Association between bleeding events and in-hospital mortality after percutaneous coronary intervention. JAMA. 2013;309(10):1022-1029. doi:10.1001/jama.2013.1556

93. Mehran R, Pocock S, Nikolsky E, et al. Impact of bleeding on mortality after percutaneous coronary intervention results from a patient-level pooled analysis of the REPLACE-2 (randomized evaluation of PCI linking angiomax to reduced clinical events), ACUITY (acute catheterization and urgent intervention triage strategy), and HORIZONS-AMI (harmonizing outcomes with revascularization and stents in acute myocardial infarction) trials. JACC Cardiovasc Interv. 2011;4(6):654-664. doi:10.1016/j.jcin.2011.02.011

94. Costa F, van Klaveren D, James S, et al. Derivation and validation of the predicting bleeding complications in patients undergoing stent implantation and subsequent dual antiplatelet therapy (PRECISE-DAPT) score: a pooled analysis of individual-patient datasets from clinical trials. Lancet. 2017;389(10073):1025-1034. doi:10.1016/S0140-6736(17)30397-5

95. Yeh RW, Secemsky EA, Kereiakes DJ, et al. Development and validation of a prediction rule for benefit and harm of dual antiplatelet therapy beyond 1 year after percutaneous coronary intervention. JAMA. 2016;315(16):1735-1749. doi:10.1001/jama.2016.3775

International Journal of General Medicine

\section{Publish your work in this journal}

The International Journal of General Medicine is an international, peer-reviewed open-access journal that focuses on general and internal medicine, pathogenesis, epidemiology, diagnosis, monitoring and treatment protocols. The journal is characterized by the rapid reporting of reviews, original research and clinical studies across all disease areas. The manuscript management system is completely online and includes a very quick and fair peer-review system, which is all easy to use. Visit http://www.dovepress.com/testimonials.php to read real quotes from published authors.

Submit your manuscript here: https://www.dovepress.com/international-journal-of-general-medicine-journal 